\title{
Men at work: Grinding stone production by the experts and others in northern Ethiopia
}

\author{
Laurie Nixon-Darcus ${ }^{1}$, Yemane Meresa ${ }^{2}$ \\ 1. Simon Fraser University. 8888 University Drive, Burnaby, BC, V5A 1S6. Canada. Email: ldarcus@sfu.ca \\ 2. Archaeology and Heritage Management, Aksum University, P. O.Box 1010, Aksum, Ethiopia. \\ Email: yemu.m2002@gmail.com
}

\begin{abstract}
:
It is necessary to access the oral forms of local histories often held in traditional African communities to help us understand the African past and avoid framing interpretations solely in terms of Western epistemologies. Ethnoarchaeological fieldwork was carried out in villages in the Gulo Makeda region of northeastern Tigrai, northern Ethiopia, where access to mechanical mills has only been available in the last few decades. Individuals in this area still have knowledge and memory of manufacturing, using and discarding grinding stones. Interviews were held with male advisors who shared their knowledge and expertise about the entire process of manufacturing grinding stones. To move beyond understanding just the technical aspects of grinding stone manufacturing (what and how), the theory and methods associated with the chaîne opératoire and design theory were incorporated into the research to allow discovery of intricate socio-economic interrelationships (how and why) that exist through grinding manufacture within this culture. Manufacturing offers opportunities for socialization, cooperation and community engagement.

Through ethnoarchaeology it became clear that the manufacturing of grinding stones in northeastern Tigrai is a complex process requiring design decisions, skills, knowledge, and social interaction that builds interpersonal relationships. By arranging two separate manufacturing sessions, one with experts and one with non-experts, comparisons were made of technological and social differences between experts and non-experts. The individuals who are experts in manufacturing grinding stones made higher quality grinding stones than the non-experts. The experts are also afforded a special respect by others, as they are the creators of the technology "necessary for life" in a culture traditionally dependent on cereal flours for sustenance. Potentially this respect for experts could be true for the past as well. Since the grinding stone artifacts from Mezber are large stones, likely meant to produce significant amounts of flour, they would have been important to daily life. Those who manufactured these tools important for subsistence would likely have been considered important individuals in the community.
\end{abstract}

Keywords: grinding stones; manufacturing; production; ethnoarchaeology; Ethiopia

Published by the School of History, Classics and Archaeology, University of Edinburgh ISSN: 2055-0472. URL: http://journals.ed.ac.uk/lithicstudies/

This work is licensed under a Creative Commons Attribution 2.5 UK: Scotland License. 


\section{Introduction}

\subsection{Grinding Stones}

Grinding stones, also known as saddle querns, slabs or matate (lower grinding stone in a pair of grinding implements) and mano (top or handstone), have a long history of use by humans in food processing. Examples include Old World pigment grinding stones recovered dating to Middle Stone Age in Africa (McBrearty \& Brooks 2000) and New World Pleistocene seed grinding implements from Australia dating to 65,000 BP (Clarkson et al. 2017). What appears to be a simple instrument comprised of a basin-shaped stone slab and a smaller hand-held stone used to grind cereals into flour plus for grinding other materials, is actually a world-wide technology which has played a central role in the lives of women and men for millennia (Figure 1).

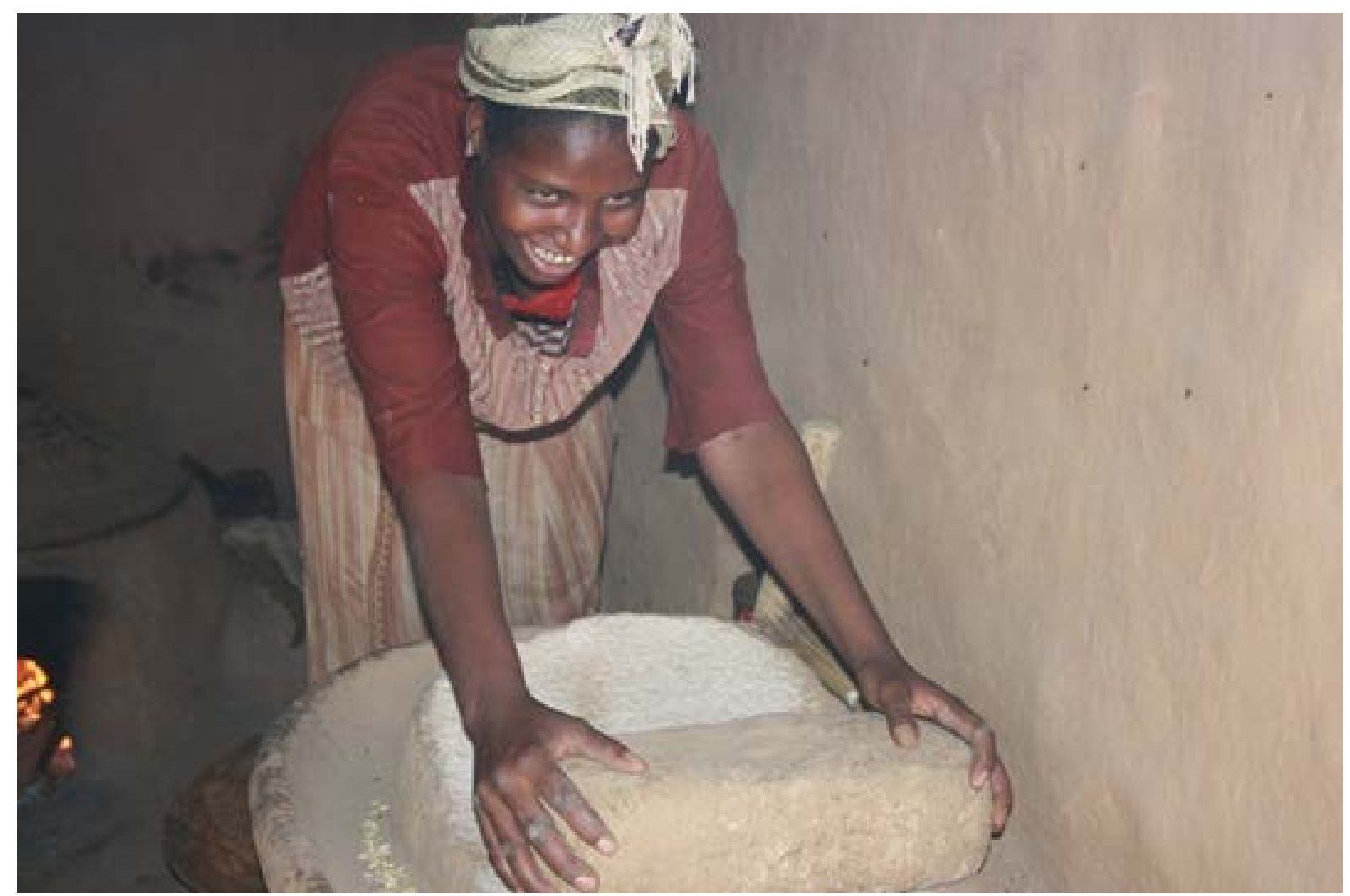

Figure 1. Northeastern Tigrai woman grinding flour with a mațhan (quern) and madit (handstone).

\subsection{Location \& overview}

Northeastern Tigrai presents a unique opportunity to document the last days of one of the most long-lived and continuously used human technological innovations. The introduction of electric or diesel flour mills in Ethiopia, and in other developing countries, makes this a fast disappearing technology. Soon there will be no living practitioners as cultures around the world continue to transition to mechanical means to process grains. In the spring of 2011, a programme of ethnoarchaeological research focussing on grinding stone production and use was initiated by the Eastern Tigrai Archaeological Project (ETAP) in northeastern Ethiopia (Figure 2) in Gulo Makeda woreda (district). This paper reports on one component of this research, namely the manufacture of saddle querns (maţhan) and handstones (madit).

In this region, grinding stone production has been part of the technological repertoire of craftsmen since at least the pre-Aksumite times. Handstones have been recovered from as early as the beginning of the pre-Aksumite period circa 1600 BCE and querns have been 
recovered from as early as circa. 600 BCE, the Middle pre-Aksumite period. In Gulo Makeda grinding stones are still used in some houses and recent manufacturing of grinding stones has taken place. The goal of the study within this region was to witness and understand the manufacturing of grinding stones from a technical and socio-economic perspective. Fortunately, several surviving artisans were located and kindly agreed to collaborate with ETAP, sharing their knowledge about grinding stone production. In a neighboring area of Gulo Makeda, three men confirmed they knew how to make grinding stones, enabling the witnessing of a second production session. These men from the neighboring area were not considered manufacturing experts. In addition, interviews were conducted with the artisans (master craftsmen or experts) and eighteen other men who had knowledge of the manufacturing process. Two of these men took us to Gerahu (Grat) Saharti quarry, where interviews and observations were conducted. It was during this quarry visit that we received our first lesson in raw material selection.

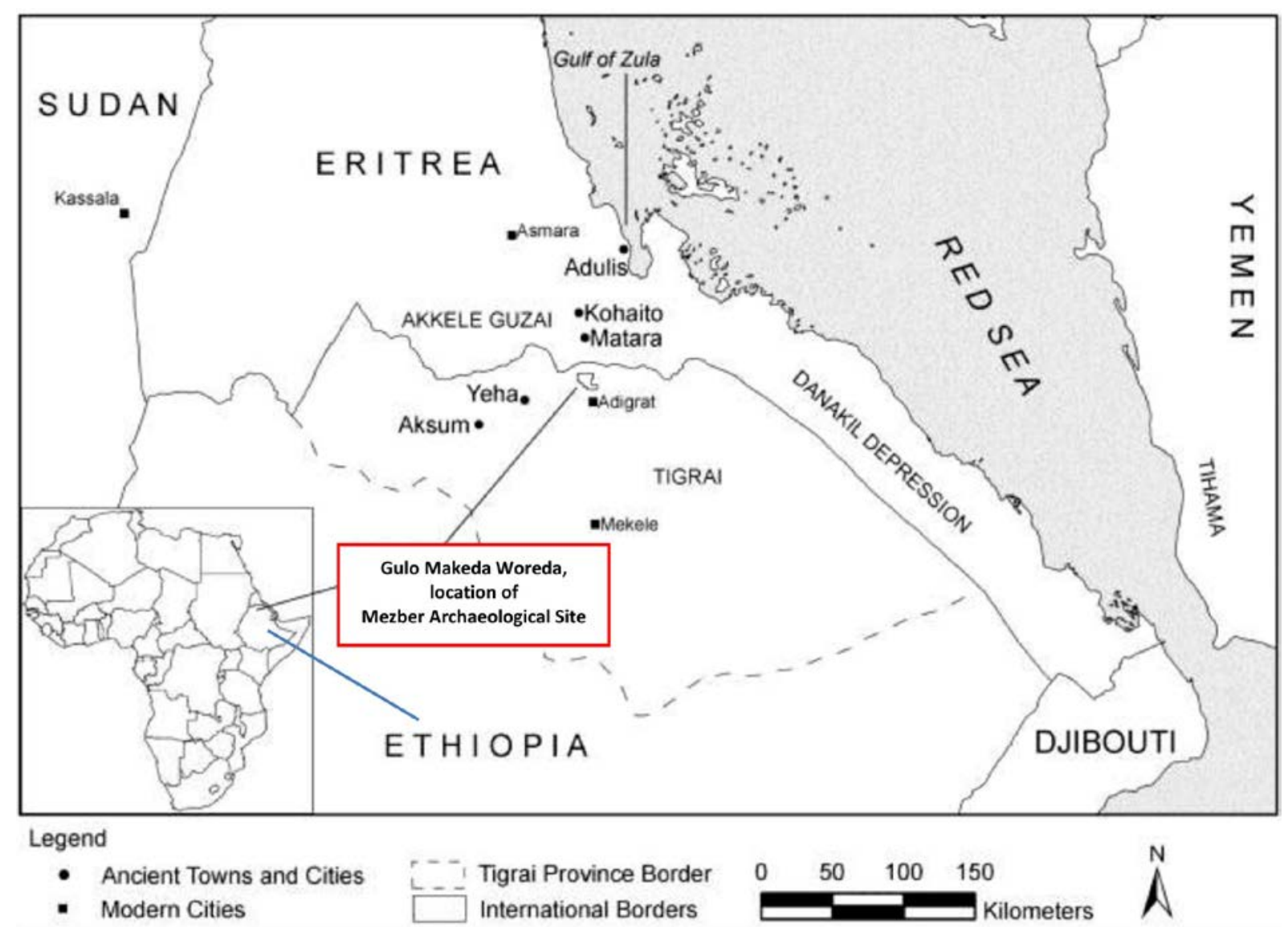

Figure 2. Map of ETAP location. Map by Michael Harrower.

\section{Theoretical framework and background}

\subsection{Design theory and chaîne opératoire}

In witnessing the process of raw material selection and manufacturing of the maţhan and madit, it was evident that decisions were being made between options available to ensure the best possible outcome. This study incorporated the use of Design Theory (Horsfall 1979; 1987: 333; Jones 1970: 3) to better understand the constraints, opportunities, and decisions facing manufacturers. The chaîne opératoire approach was employed to seek to interpret the interrelationships between technology and socio-economic aspects of the northern Ethiopian culture. 
Archaeology has borrowed the concepts of Design Theory from the engineering, industrial and architectural sciences where it was developed to explain the processes that lead to the manufacture of a final product or the development of a specific technique (Horsfall 1987: 333; Jones 1970: 3). The basic premise is that a design process goes through a sequence of events that present the designer with constraints and perhaps choices between options that result in an acceptable outcome to the end consumer who is expecting something truly useful for the purpose intended, or to solve an activity related or adaptive problem (Horsfall 1987: 333-334; Pye 1978: 11). Problems could be related to economic, technological, social or ideological behaviors (or a combination thereof). The solutions arrived at will be context specific because design is an activity which is defined by the social milieu within which the activity takes place (Margolin 1989: 7). Design is important when attempting interpretation of material culture, as it reflects behaviors that are formulated and maintained (and in some cases changed) through contextual cultural systems. Adams (2014: 18) recommends that function is better defined by design than form. A simple change in design could ultimately change a tool's function even if the form is similar. For example, in this study, two types of base stones were identified and though they looked very similar at first glance, a slightly thinner madqos was the reflection of a different use (see Table 1: use of madqos). A Design Theory framework can be applied to study the manufacture of grinding stones to begin to understand the design process and how this reflects past human culture and behaviors (Horsfall 1979; 1987).

Table 1. Tigrinya terms. Note: Transliterations for many Tigrinyan terms were provided by Professor Yaqob Beyene, Professor Emeritus, Department of Asia, Africa, and the Mediterranean, University of Naples, and additional Tigrinyan terms were translated by Yemane Maresa and Habtamu Mekonnen Taddesse. Pronunciations are as were heard orally in interviews.

\begin{tabular}{lll}
\hline Transliteration & Pronunciation & Translation and Use \\
mațhan & me-tə-han & Quern or base stone for grinding cereals into flour \\
med-kōs & $\begin{array}{l}\text { Quern or base stone for grinding spices, peppers, salt, wet } \\
\text { corn }\end{array}$ \\
$\begin{array}{l}\text { madit } \\
\text { wedimadqos }\end{array}$ & $\begin{array}{l}\text { ma-deet } \\
\text { we-di-mad- }\end{array}$ & $\begin{array}{l}\text { Handstone used with mațhan } \\
\text { kōs }\end{array}$ \\
$\begin{array}{l}\text { mawquari } \\
\text { melde }\end{array}$ & mel-ka-rā & Hammerstone for rehabilitating grinding surfaces \\
\end{tabular}

The chaîne opératoire (operational chain) is a means to break down each technological process into its elements (links in the chain). The interrelationships between the links of the chain focus on the technology itself, the sociocultural, the political, and the ideological expressed through human courses of action and speech (Leroi-Gourhan 1993). Like Design Theory, the chaîne opératoire takes a systems approach - exploring the integrations of different cultural systems such as technology and social systems - by attempting to define those cultural interrelationships. A craftsperson will make technical choices based on social choices that are learned as members of a particular community. In reconstructing the dynamics of the past, such as relationships between grinding technology and the socioeconomic aspects of northern Ethiopian culture, through the application of the chaîne opératoire, there are possibilities of conceptualizing knowledge, skills, and values that contributed to and were reflected through the creation of the material culture by past artisans.

Both Design Theory and chaîne opératoire act as Middle Range Theories when applied to archaeology and both rely on ethnographic inquiry to draw analogies about the past. Linking anthropological behaviors witnessed to the associated anthropological material 
culture and then comparing that material culture to the artifacts recovered for similarities, we can create interpretations of past human behaviors (Binford 1977). For this reason, ethnoarchaeology was used in this research to understand grinding equipment manufacture from a broader cultural perspective.

In considering the chaîne opératoire of the grinding stones in this research, attention was paid to the processes of raw material selection, the energy expended, and techniques employed for the shaping and transformation of a boulder into usable cultural products - the mațhan and madit (see Table 1 for a glossary of all Tigryna terms). In addition, the associated interpersonal relationships displayed during the process, the skills and knowledge displayed, and the values of respect that were afforded to the master craftsmen were observed.

\subsection{Background}

Excavations conducted by ETAP at the archaeological site of Mezber (Figure 2) have uncovered over 120 grinding stones between 2007-12. All grinding stones date to preAksumite times (circa 1600 BCE - 1 BCE, CE). This sample includes complete and broken artifacts and can be classified under four categories: basal stones are either 1 . maţhan or 2 . madqos; and top handstones are either 3. madit or 4. wedimadqos. Through interviews it was learned that the mațhan was used for grinding of cereals into flours while the madqos was used for grinding spices, salt, peppers, and wet grinding (second grinding) of corn. Typically, the madqos has a more concave grinding surface. For this study, only the mațan and madit were requested for manufacturing because when a mațhan becomes too worn for grinding cereals, it is recycled and reused as a madqos.

Mezber is situated in a remote corner of northern Ethiopia. The region relies heavily on subsistence agriculture, regularly supplemented by food aid. There is no running water or electricity, and transportation is normally by foot, though donkeys and horses are used as pack animals. Oxen are used for ploughing of fields.

Farmers in this northern area continue to thresh crops using oxen and process grains through a laborious method of hand-winnowing and milling grains into flour using grinding stones. Through interviews it was learned that grinding stones are being used less and less with the introduction in the last decade of grinding mills (D'Andrea 2008; D'Andrea et al. 1997; D’Andrea \& Haile 2002; D’Andrea \& Wadge 2011). Even so, every home visited in this research had at least one mațhan and madit that were at least used occasionally.

In the village of Tsa'eda Hamed there are two highly respected expert craftsmen who make grinding stones, Haleka Tewoeldebrahn Beyene (81 years old at that time) and Haleka Gebreselassie Gebreyesus (71 years old). Both informants learned the trade from their fathers, who learned from their fathers. Until recently, grinding stone makers were highly respected because they had knowledge to manufacture, what was referred to by informants as, tools "necessary for life": without grinding stones "people would starve” (note: quotations are from interviews conducted in 2012).

With the introduction of electric and diesel four mills in the last decades and the declining need for grinding stones in the villages, both master craftsmen described the lack of interest by their sons to become expert grinding stone makers. Instead they were teaching any men who wanted to learn, but the lessons were basic, lacking the more intense apprenticeship they had completed with their fathers, or would have provided to their sons. Although the knowledge of grinding stone making was being dispersed widely to men in the area, these two men remain the experts. Haleka Tewoeldebrahn and Haleka Gebreselassie kindly agreed to manufacture a mațhan and madit so that we could observe the process and have a newly manufactured sample for the artifact collection to compare with archaeological samples. 


\section{Data results: Manufacturing a Mațhan (quern)}

\subsection{Applying chaîne opératoire and design theory to the manufacturing process}

Applying the chaîne opératoire approach, the manufacturing process has been broken down into stages to identify the steps taken and the interrelationships between technology and socio-economic constructs that are formed or supported through the manufacturing. From procurement of raw materials, through breaking the stone, shaping the stone and finishing, concepts of Design Theory have been applied to draw out constraints, options, and decisionmaking processes that occur through the manufacturing process.

\subsection{Procuring the raw materials}

\subsubsection{Quarry sites}

Several investigators have focused on grinding stone manufacturing on the basis of material remains found at archaeological quarry sites (Abadi-Reiss \& Rosen 2008; Conlee 2000; Field et al. 2003; Schneider 1996; Smith et al. 2010). Efforts have been made to infer past methods of manufacturing by examination of the debitage left behind at sites where the raw material to produce grinding stones is acquired. As in many studies of archaeology, interpretations are often based on what meaning can be derived solely from the material culture left behind and though providing useful information, there may be opportunities to strengthen interpretations through the use of ethnoarchaeology (for another Ethiopian ethnographic account see Teklu 2012).

There are three main quarry sites near the villages for raw material. The quarry sites with the preferred raw materials were identified as:

Gerahu (Grat) Saharti, Figure 3 (claims are that this site has the highest quality and quantity of the material suitable for grinding stones) (20-30 minute walk uphill from most residences in the immediate valley where Mezber is located);

Nizibat lidet (2 hours walk away);

Libeda Gebrezgi (near Haleka Tehwoeldebrahn's house, a 10-15 minute walk uphill from most residents in the immediate valley).

Two of the quarry sites are within a thirty minute or less walk from the adjacent villages, and distance to raw material does constitute a design constraint as consideration is given to the distance for transporting the heavy grinding stones. We were advised by informants that one might procure stone of lesser quality close to one's home if it is required quickly, or if one does not have access to the labour needed to transport the mațhan back from a prime quarry site. In this latter case quality may be sacrificed to accommodate the need for nearby materials - a design decision.

It should be noted that the selection of a procurement site was based not only on the owner's access, but also on the amount of energy that would need to be expended for travelling and transporting the finished product. The heavy weight of the finished product was clearly a constraint to be considered in the design process. Although we had heard in interviews that Gerahu (Grat) Saharti, had the best quality rock, the quarry chosen, Libeda Gebrezgi, offered much closer proximity to the final delivery destination, and with the manufacturer also owning the land no special requests for permission were required. 


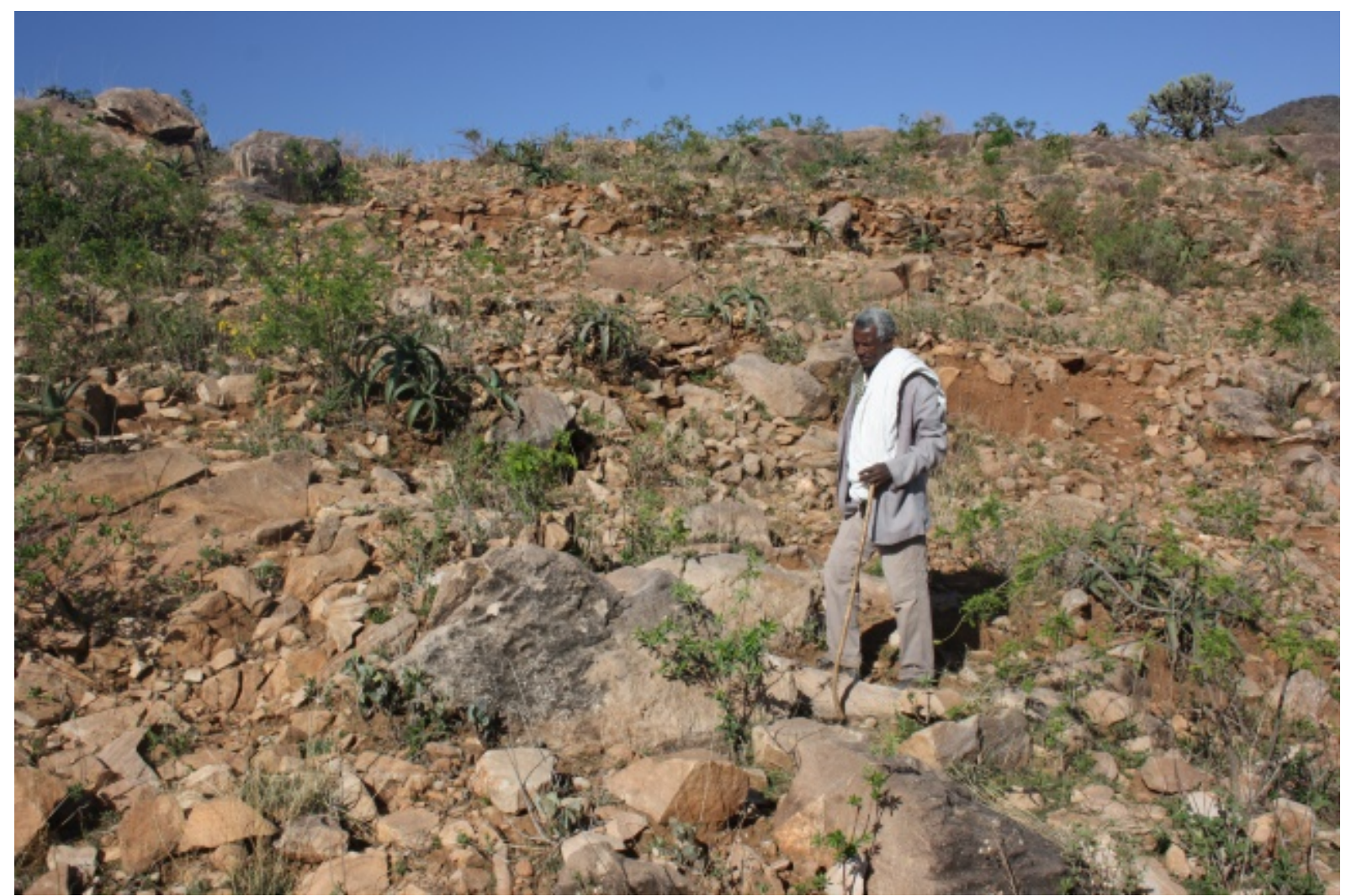

Figure 3. The Gerahu (Grat) Saharti Quarry Site.

Haleka Tehwoeldebrahn owns Lebida Gebrezgi, the land adjacent to his home, where good sandstone raw material can be found and from which he selected the stone to manufacture our grinding equipment. He explained that this is one of the key quarry sites with a good inventory of stone and we observed evidence of prior manufacturing in this location based on debitage scatter.

In addition to his own use of raw materials from Lebida Gebrezgi to manufacture grinding stones for others, Haleka Tehwoeldebrahn explained he will grant people permission to access the high quality stone for themselves and in return for the access granted he receives what he referred to as "good relations"; there is no exchange of money. This type of access for raw materials, in exchange for favorable social relations was also confirmed through other interviews. An owner granting access to his property can expect the favour to be returned, for instance a man granted access for raw materials may in return offer labour to the property owner for house repairs, field work, harvesting, etc. If someone from another territory were to ask for access, the owner may request a cash payment, as the reciprocal exchange of labour at a later date is unlikely due to the receiver being inaccessible at a distance. In contrast, Antelope Hill, the largest known quarry site in the United States, was neutral territory and accessed by multiple cultural groups (Schneider \& Altschul 2000).

\subsubsection{Raw material selection}

According to Design Theory, one of the constraints faced by manufacturers relates to raw material decisions such as choosing the most suitable raw material from what is available to them. The main sources of boulders large enough for mațhan manufacturing in the valley are basalt and sandstone. The question had been asked, what kind of stone is best suited for mațan production? It was difficult for the men to verbalize the qualities they looked for. However, when they pointed out to us the preferred stone it became clear that the highly favoured stone of choice for grinding stones in this region is quartzitic sandstone that through 
the metamorphic process is approaching quartzite. This stone displays pebble sized grains of quartz strongly welded together (Figure 4). The quartz inclusions provide a coarse but strong surface for grinding flours. For further information on the raw materials used and their properties see Nixon-Darcus (2014: 81-84). Fratt \& Biancaniello (1993) document the variation in raw material stone matrix in the Southwest U.S. and how it influenced selection of material for grinding stones depending on the intended use.

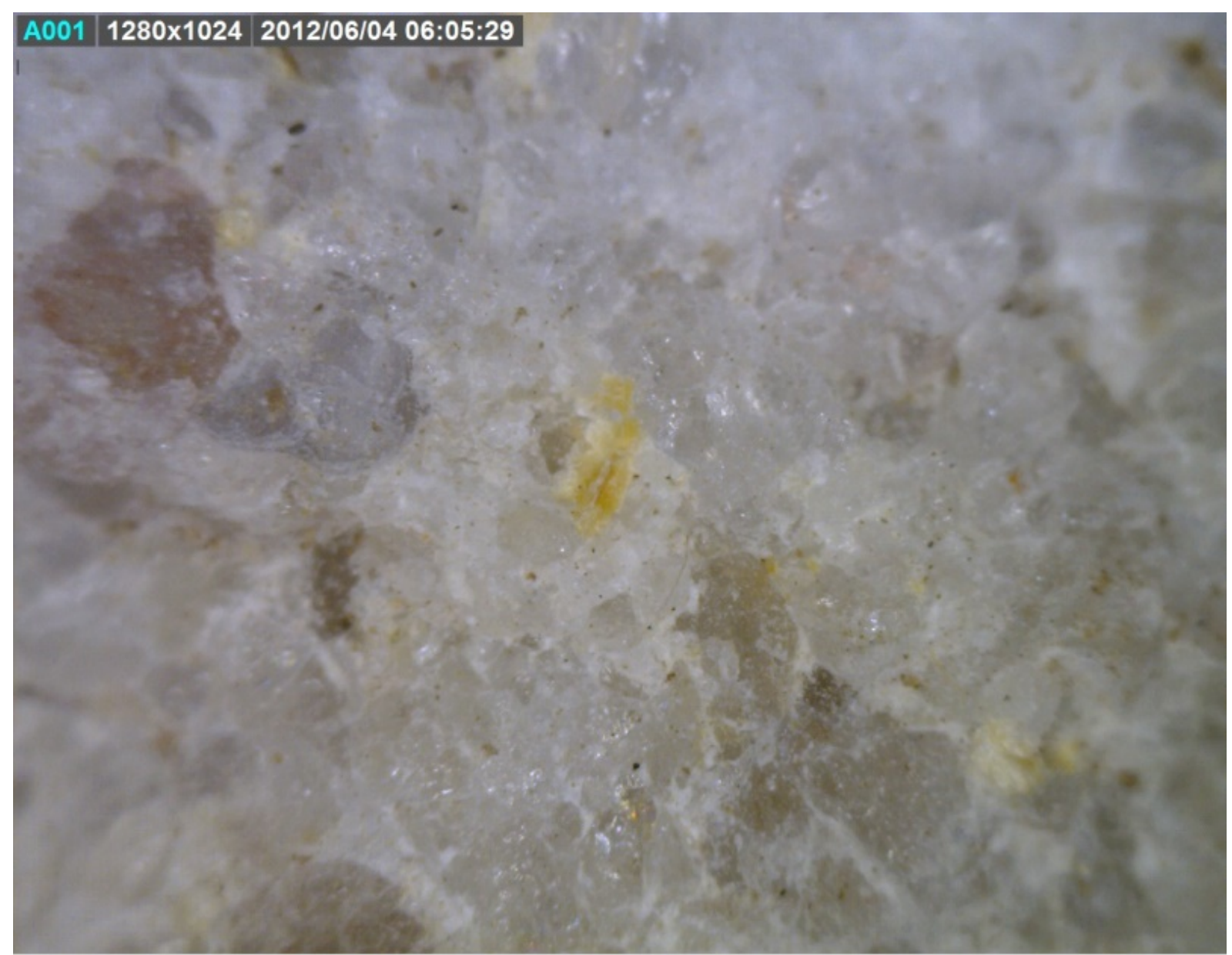

new metahan $55 \mathrm{X}$

Figure 4. The raw material used for production - quartzitic sandstone.

\subsection{First stage of manufacturing - Excavation \& 'breaking' the stone}

The sandstone boulder of choice was buried in an embankment with another boulder directly above it, resting on the selected boulder so it would need to also be excavated (Figure 5). It would prove difficult to excavate. Haleka Tehwoeldebrahn and Haleka Gebreselassie had recruited two younger men to participate in the manufacturing process, a son and a neighbor. During excavation we witnessed ongoing discussions and conversations relating to strategizing the best means to excavate, for instance where to lay blows with the sledge hammer (modesha), where to place leverage with the pry bar (melaquino) and shovels (magafias) to move and release the boulders from the embankment (Figure 6). This is another constraint faced by the manufacturers - the tools available; they have no power tools, and in the past, they would have had further constraints with only stone tools available. Planning how to implement the tools appeared to be key decisions as discussion around tool use were constant throughout the process. The list of tools is found in Table 2. This kind of collaboration among the four individuals was continuous throughout the first day, and it 
should be noted that often the advice of the two experts was sought for guidance on best practises. For example, with a sledge hammer, heavy blows were strategically placed where the master craftsmen had identified the preferred lines for fracturing the stone. Quartzitic sandstone does not have defined bedding planes that will cause a specific type of fracture, so the experts were planning how they wanted to start the cracking of the stone because they could then control how the stone would fracture in a manner best suited for crafting a maţhan. In addition, it was observed that the two younger men took on most of the heavier, strenuous work leaving the experts to supervise and provide guidance, though often both experts also took the tools themselves to contribute to the making of the mațhan and madit.

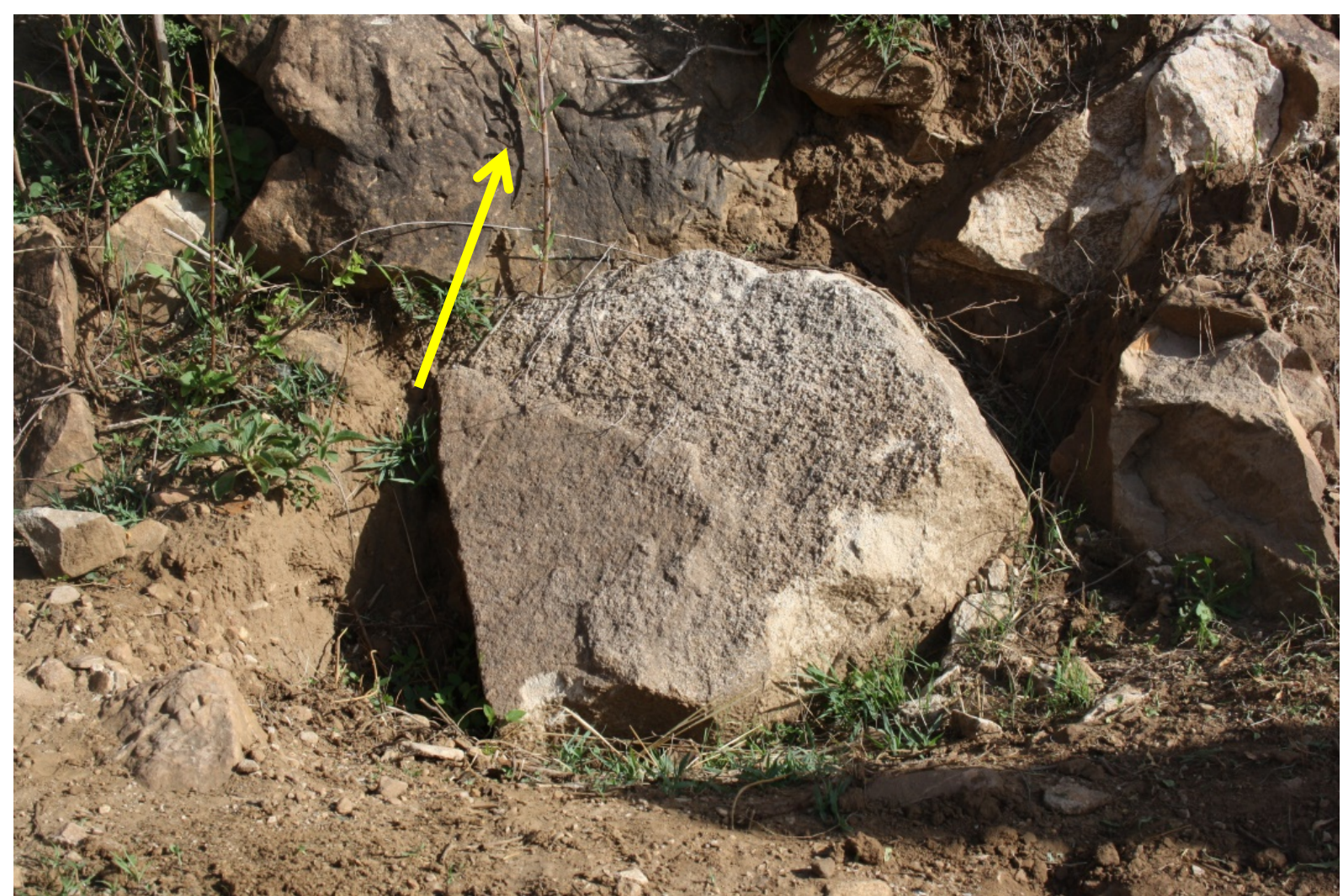

Figure 5. This lower boulder was selected for manufacturing, and the darker boulder (yellow arrow) was also excavated to enable access to lower boulder.

Much respect was shown to the experts, indicative of the expertise they held. One of the values observed, and discussed during ethnographic interviews, was the social status of grinding stone master craftsmen. Haleka Tehwoeldebrahn and Haleka Gebreselassie were well respected men in this society, because they held a special knowledge so important for subsistence. Grinding stones were necessary for life in that they were the instrument used to generate the main food staple. As the need for grinding stones decreased over the last decade because of the introduction of mechanical mills, the highly held social status of the master craftsman also diminished. Though they were both still well respected, they did not continue to hold an elevated status in the community. 


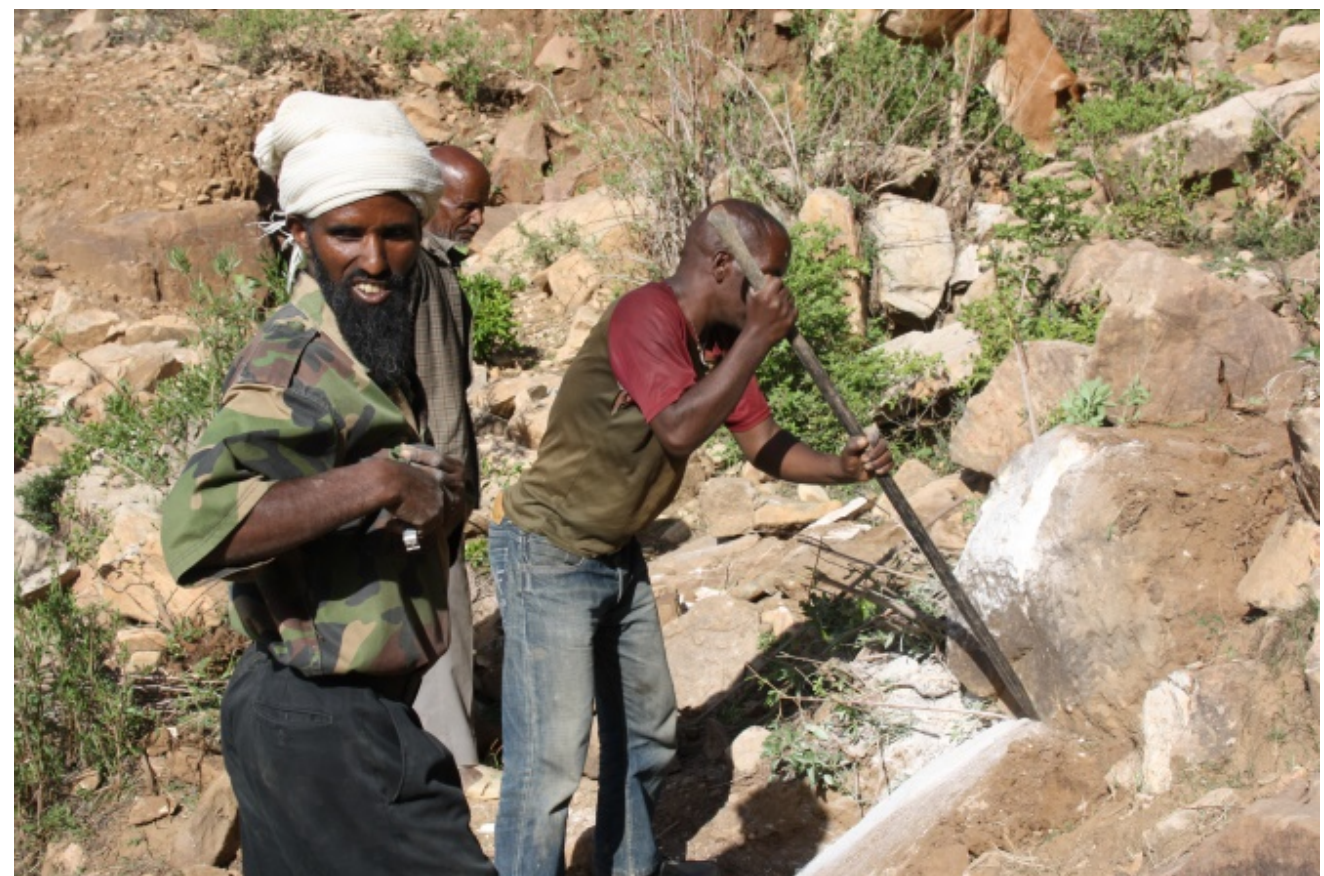

Figure 6. Men applying leverage with a pry bar to extract the boulder during excavation.

Table 2. List of tools. *The metal tools have taken on Italian terms for the Tigrinya speaking people of this region. It is likely that these tools were introduced by the Italians who have had a long presence in Ethiopia. - In the second manufacturing process with the non-experts, we did observe stones being used for some processing and smoothing of the surfaces. It could be that they did not have the necessary metal tools because they were not experts.

\begin{tabular}{lllll}
\hline $\begin{array}{l}\text { Tools Used in Manufacturing: } \\
\text { According to Interviews } \\
\text { (n=15) }\end{array}$ & Responses & $\%$ & $\begin{array}{l}\text { Observed } \\
\text { Used by } \\
\text { Experts }\end{array}$ & $\begin{array}{l}\text { Observed } \\
\text { Used by non- } \\
\text { Experts }\end{array}$ \\
\hline $\begin{array}{l}\text { modesha (sledge or large } \\
\text { hammer) }\end{array}$ & 14 & 93 & $\mathrm{~V}$ & $\mathrm{~V}$ \\
$\begin{array}{l}\text { martello (small hammer) } \\
\text { melaquino (pry bar) }\end{array}$ & 12 & 80 & $\mathrm{~V}$ & $\mathrm{~V}$ \\
$\begin{array}{l}\text { magafia (shovel) } \\
\text { scarpello or punta (wedge or } \\
\text { chisel) for splitting rock }\end{array}$ & 12 & 80 & $\mathrm{~V}$ & $\mathrm{~V}$ \\
$\begin{array}{l}\text { mehu-ati (axe) (for excavation } \\
\text { \& trimming) }\end{array}$ & 5 & 60 & $\mathrm{~V}$ & $\mathrm{~V}$ \\
$\begin{array}{l}\text { mebarro (large hoe) } \\
\text { chukarra (small hoe) }\end{array}$ & 47 & $\mathrm{~V}$ & with handle \\
$\begin{array}{l}\text { mawqari (hammer stone used } \\
\text { in earlier times, now replaced }\end{array}$ & 1 & 33 & & $\mathrm{~V}$ \\
$\begin{array}{l}\text { with metal tools*) } \\
\text { small pick axe (for finishing) }\end{array}$ & 2 & 13 & & $\mathrm{~V}$ \\
long wooden stick & 7 & & \\
\hline
\end{tabular}

During the breaking of the stone in two, we witnessed Haleka Tehwoeldebrahn cleaning off the top end of the stone with a branch of leaves from a nearby bush and tapping the stone with the small hammer (martello) in various places, observing the structure and composition of the stone, to determine how it would break. He said he was looking for the "weakspots", in 
the sandstone. By tapping a rock, audible sounds can alert one to existing internal fractures that might impede fracture plans (Sandgathe 2013, personal communication). He had learned this knowledge about how rocks react to force from his father. The two younger men made a few hammer blows in various areas to test the reaction of the stone, while the two older men observed and made recommendations for the next set of hammer blows (Figure 7). This was a difficult boulder to fracture, and it was explained to us that the difficulty in fracturing was indicative of good material for grinding stones - "strong rock for grinding”. Interviews with non-expert grinding stone makers revealed that if they found the rock too difficult to break, they could fire the rock to help with fracturing.

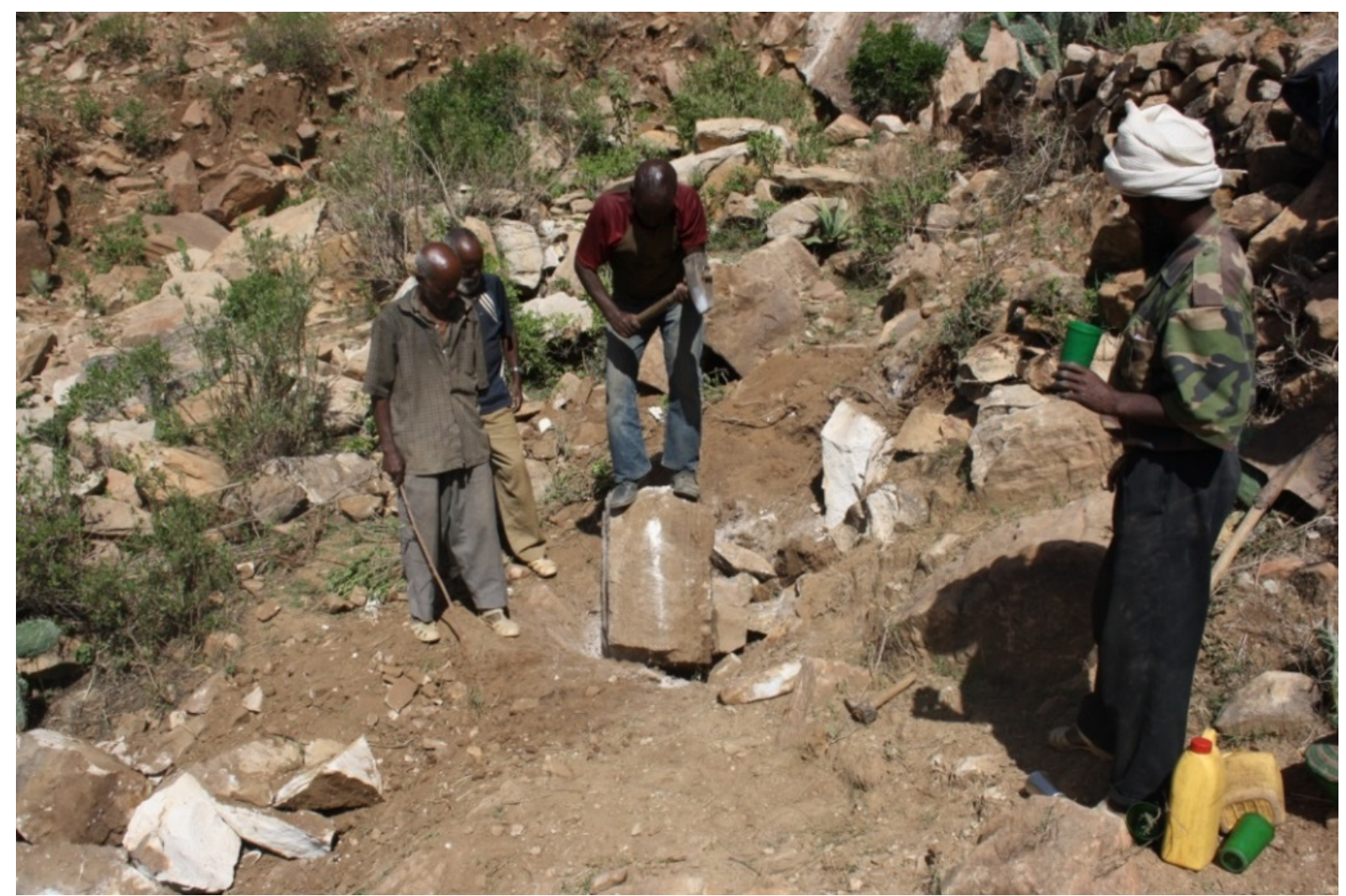

Figure 7. One man hammering in attempts to break the stone in half.

Once the initial fracture line became wide enough, metal v-shaped wedges (scarpello or punta) were inserted into the crack (Figure 8) and blows with the sledge hammer further expanded the fracture until the boulder finally cracked into two halves. The resulting ventral sides had relatively flat surfaces along the fracture line and would be used for the grinding surface.

\subsection{Second stage of manufacturing - shaping the Mațhan quern (block preparation)}

After the boulder was cracked in half, forming the desired shape of the mathan began (Figures 9 and 10). In reducing the block, blows were carefully placed with the knowledge of how the pieces would fracture away from the main stone. The men were well trained to know hammer techniques to remove large chunks and flake around the perimeter of the stone without cracking it or causing damage. Less forceful blows of the sledge hammer were used to shape the ends. On several occasions during the trimming and shaping, the men adjusted the position of the stone by supporting it with other stones to raise or lean it, or by placing it in a desired position in the loose dirt around it to remove pieces (see example of a support stone in Figure 10). It was explained that this was done to ensure that while trimming they do 
not break the stone accidently and ruin the potential for manufacturing a mațan. Schneider (1996) also describes the act of using supports in manufacturing "to properly position and stabilize the piece for reduction".

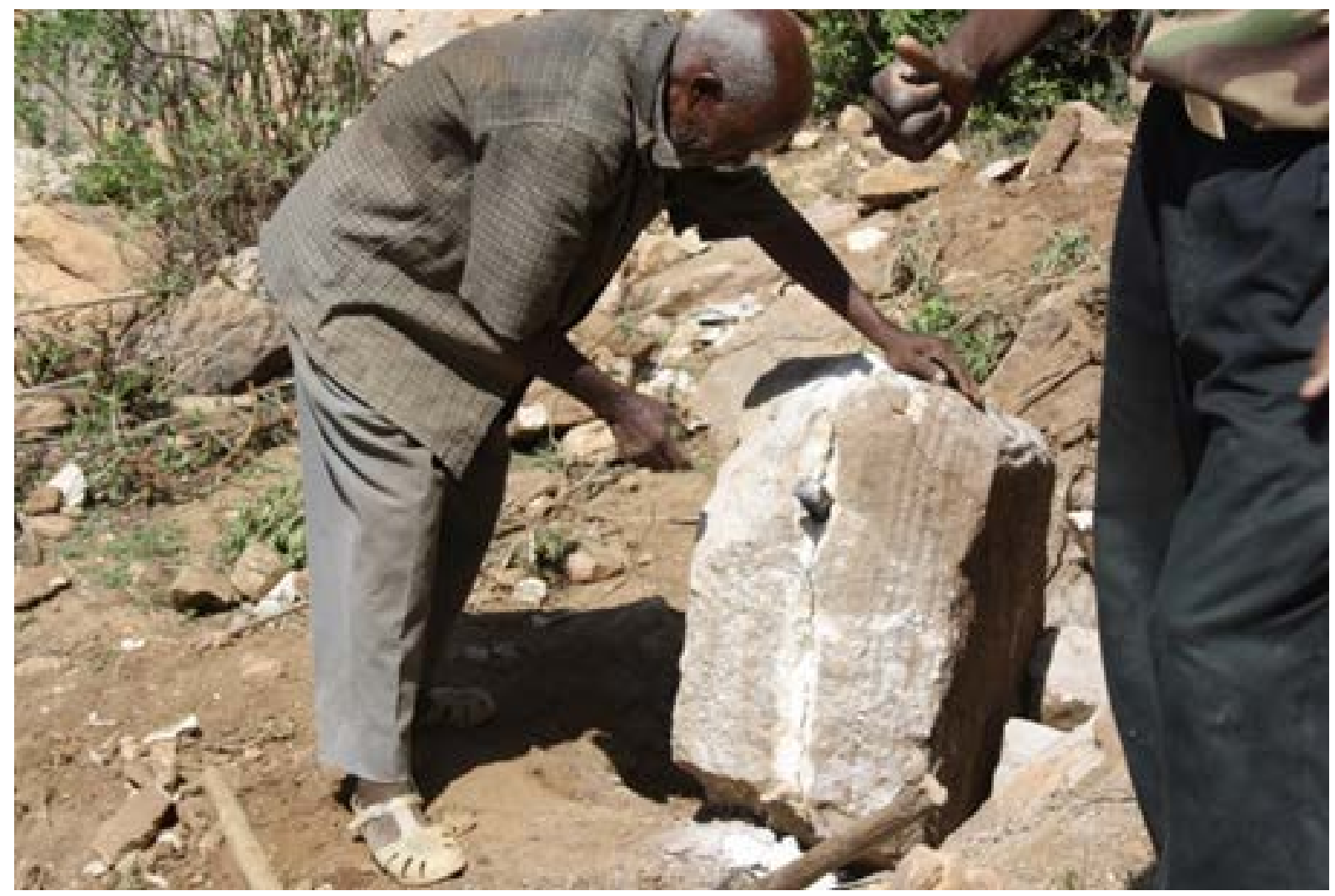

Figure 8. Haleka Tehwoelde Brahn Beyene (expert) using wedges and a sledge hammer to 'break' the boulder in two.

In this manufacturing process, Design Theory was reflected in the decisions the manufacturers were making between choices and options available. They made choices about which raw materials were best suited for manufacturing. These experts considered 'cost of manufacturing'. Decisions and discussions took place as to which tool was most effective to minimize effort at various stages of production. Choices were made as to where to strike the hammer blows to achieve the best fracture results and to reduce the chance of unwanted breakage. Design choices were made about the shape and size of the finished grinding stones to ensure the finished tools would be suitable for efficient and effective grinding but also of a size manageable by the end user. This type of knowledge was again transferred from predecessors, but also learned and perfected through direct experience.

As the trimming progressed with chipping or knapping, measuring for proper size was required. It was demonstrated that the length of a mațhan should be the distance from the elbow to the tip of the middle finger - approximately half a metre, though the exact measurement would depend on the man's arm length doing the measuring. The width of the mathan should be approximately the distance from the elbow to the wrist. Also, to consider is the size of the mathan a new one would be replacing, as the new mathan would need to fit into the same table that had been previously built by the woman of the house to support her current grinding stone. It was explained that the measurements of the old mațan could be achieved by cutting sticks to the length and width of the current mațhan to bring to the quarry site. 


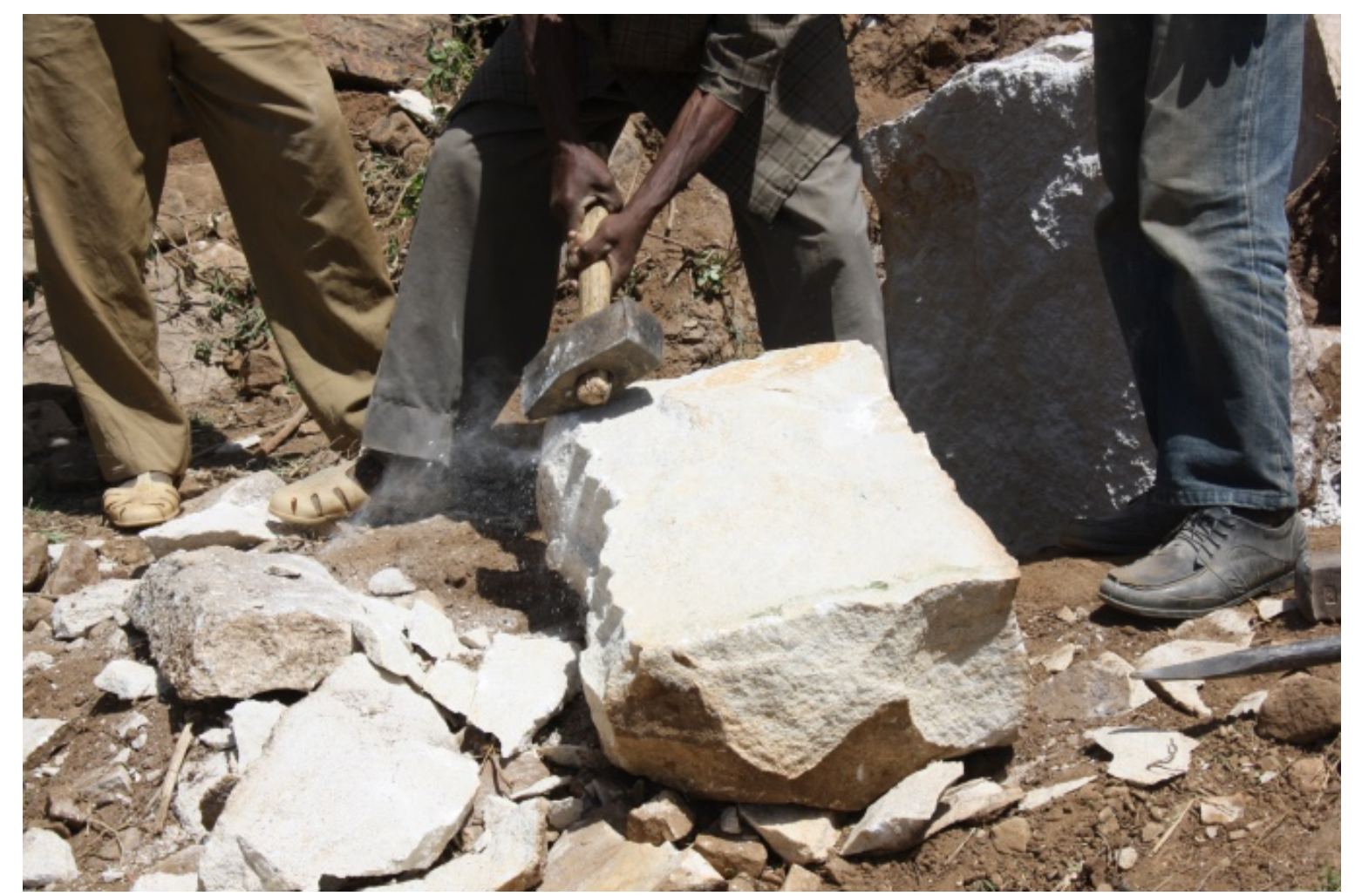

Figure 9. Haleka Tehwoelde Brahn Beyene here is trimming large flakes.

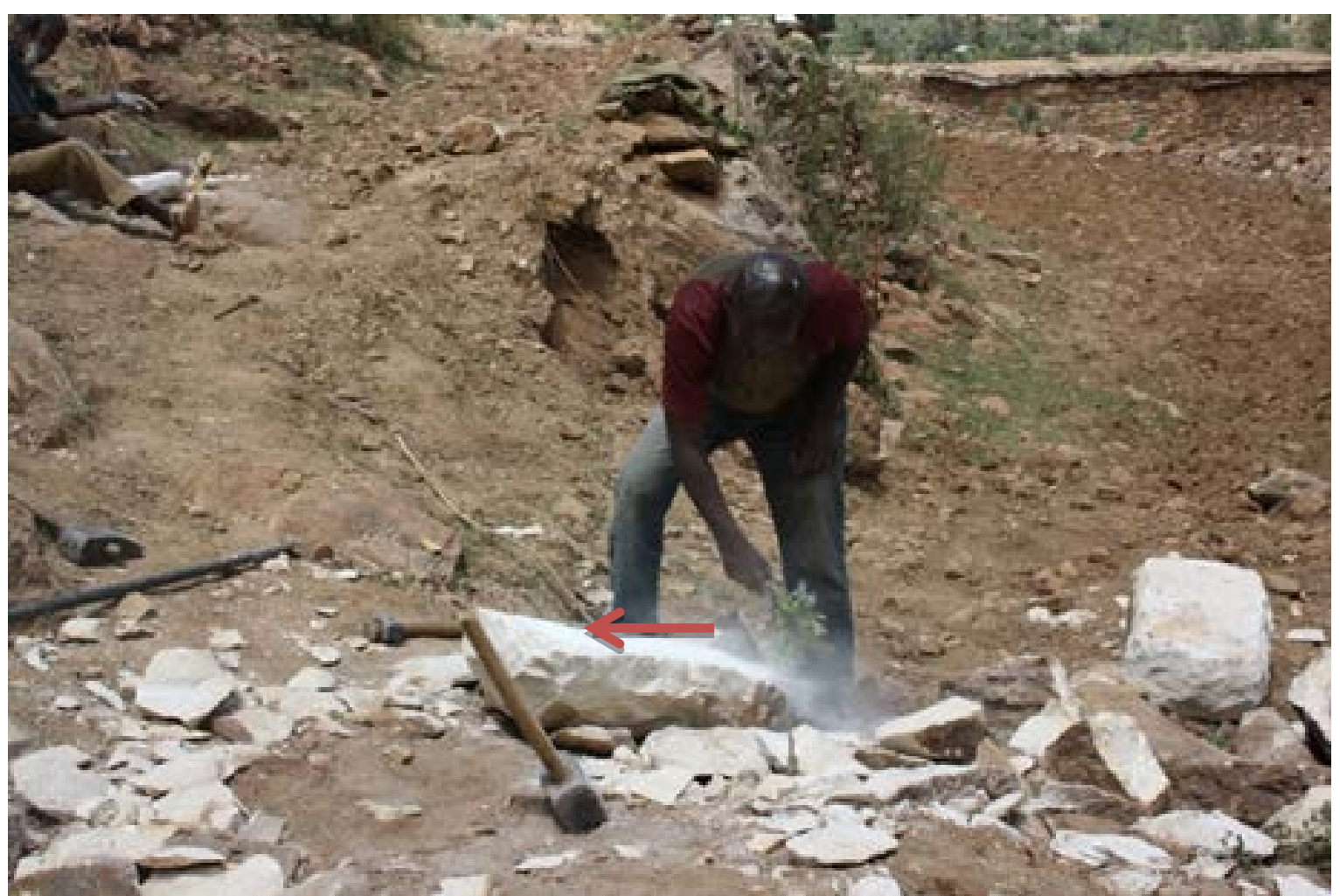

Figure 10. One of the helpers completing finer finishing of ventral (grinding) surface (note supporting stone under mațhan).

It appeared that a consistent width along the length of the mațhan was also important. A twig was broken to the size of the width in one section and moved along the length of the surface to ensure the width was consistent throughout. A branch of leaves pressed hard to the 
stone surface, left a mark where the preferred edges would be, based on these measurements. The trimming to remove precise smaller flakes was the next step, using both the sledge hammer and a smaller hammer. It became obvious that it was known by the master craftsmen who were completing the trimming exactly where to place the blows to achieve the desired shape. After one hour of trimming, the major shaping of the maţan was basically completed. The final step at this stage was to remove flake scars which straightened and smoothed the edges and flattened the ventral (grinding) surface.

\subsection{Third stage of manufacturing - Finishing the Mațhan quern}

Final finishing work (Figure 11) was done in the same location, but on a subsequent day, by the two master craftsmen. We noticed that in addition to the small hammers with rounded heads a new tool was added, a small pick ax. This was intricate work, completed with softer hammer blows, and careful use of the pick ax. Blows were made with both heads of the hammer, as well as with the side of the hammer head. In some instances, the hammer appeared to 'bounce' off the stone, likely due to the motion of the master craftsman's swing (which was too slight to effectively describe). Some blows were made at a 45 degree angle to the surface of the stone.

It was explained that the goal was to produce a "good mațan and madit". The design goal appeared to be to produce grinding surfaces that while relatively flat (versus concave) also had enough of a rough surface to enable some abrasion for effective grinding. This decision was made to ensure efficient use, and less strenuous grinding requirements by the user, as flat surfaces grind more grain with less effort than do surfaces designed differently. The unencumbered movement of the flat grinding surfaces of the madit over the mathan relieves some of the strain on women using repetitive grinding strokes (Adams 1993).

In addition, work was completed to round the proximal and distal ends, and the left and right lateral sides of the mațhan were made even straighter, and somewhat smoother. Although small flakes were falling from this finishing work, much of the debris that was coming off was dust-like.

The final finishing work actually required more time than the excavation and basic shaping of the grinding stones (Table 3). When asked how much longer it would take to make these grinding stones with stone tools, Haleka Gebreselassie replied that metal tools are better to work with because of the handles (ability to grip and manage the tool better than holding a stone), and he said that it would take five to six days to complete the manufacturing of grinding stones with stone tools, which is triple the time required if using metal tools. The introduction of metal tools reflects one change in the chaîne opératoire since former times. Using stone tools in the past would have had greater constraint implications because, as the experts explained, stone tools were heavier and more difficult to control (no handles). So, understanding the capabilities of the available stone tools and how they perform would have been acquired through the generational transfer of knowledge and ongoing experiences. In this manner, the master craftsman would have had advantages over other men who manufactured grinding stones as that transferred knowledge, accumulating through generations, was passed on to them from their master craftsman fathers. In addition, they were involved in many more instances of manufacturing so had more opportunities to improve tool use. 


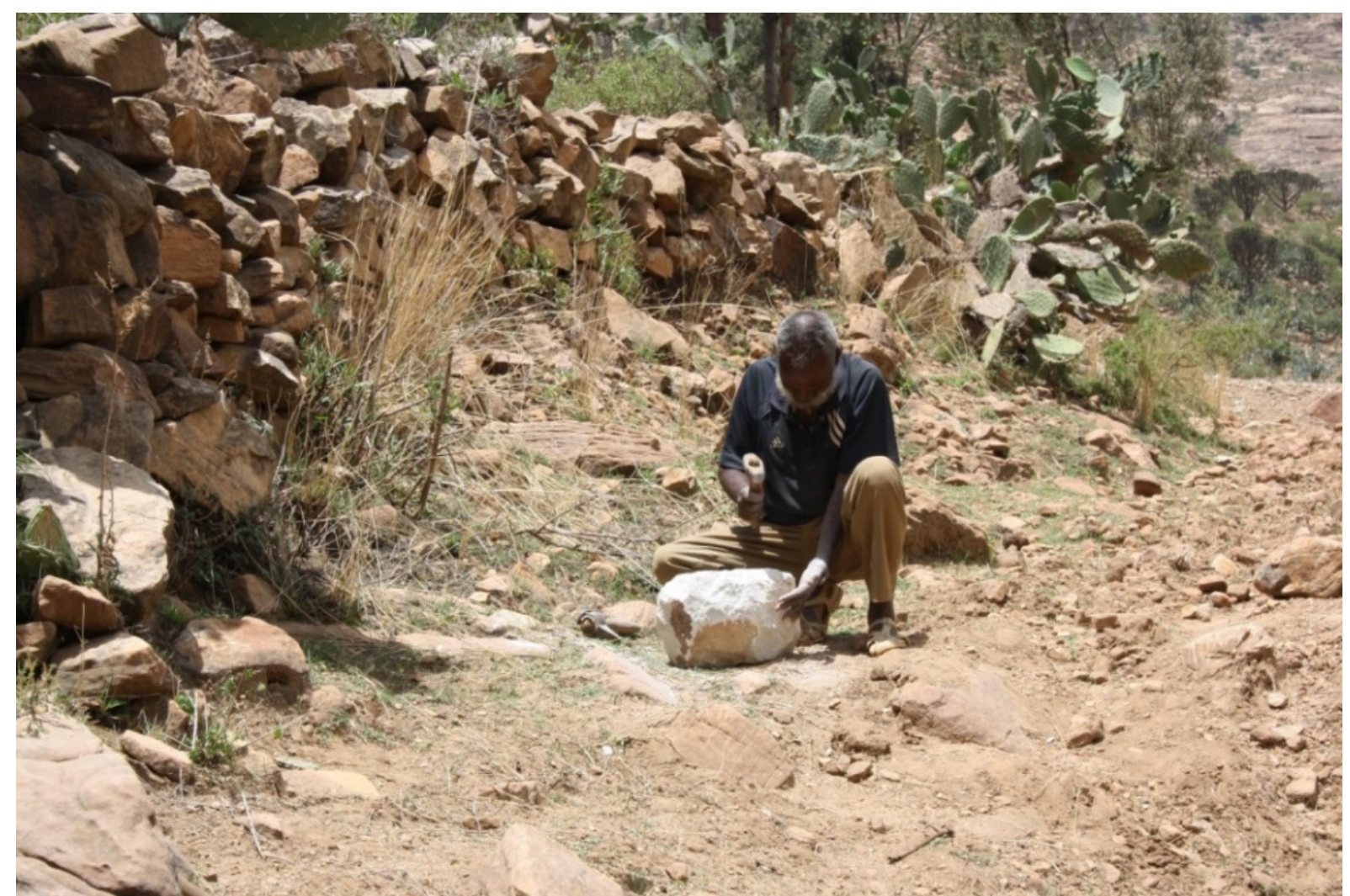

Figure 11. Haleka Gebreselassie Gebreyesus working on final finishing of Maţhan.

Table 3. Time to complete manufacturing (using metal tools).

\begin{tabular}{ll}
\hline Tasks for manufacturing mațhan (quern) & Time to complete \\
\hline Extract stone resting on top & 1 hour \\
Remove mațhan stone from bank & 20 minutes \\
Break the mațhan stone in half & 35 minutes \\
Basic trimming and shaping & 1 hour \\
Finishing work & 4 hours \\
Total Manufacturing Time & 6 hours and 55 minutes \\
\hline
\end{tabular}

When we asked the question about how long it would take to make a mațhan during interviews the answers varied considerably, anywhere from one day (typically 7 hours) if there were between two to five men involved, and two to four days of manufacturing for a person manufacturing alone. Likely this variation has to do with expertise, or attention to precision detail. For the expert led manufacturing process, four men were required for a little over half a day, and the two experts completed the finishing over another half day with one working on each of the grinding stones.

Flakes littered the ground (Figure 12), and we asked about use of the debitage. The response was that the larger flakes would be used in terracing efforts and pieces would be used in masonry work (e.g., house construction; see Figure 13), while smaller flakes would be left to mix with the soil. No partially manufactured or broken grinding stones were observed at either quarry sites visited, suggesting that in fact large chunks and flakes of this good quality stone could be used for other secondary purposes and had been hauled away. 


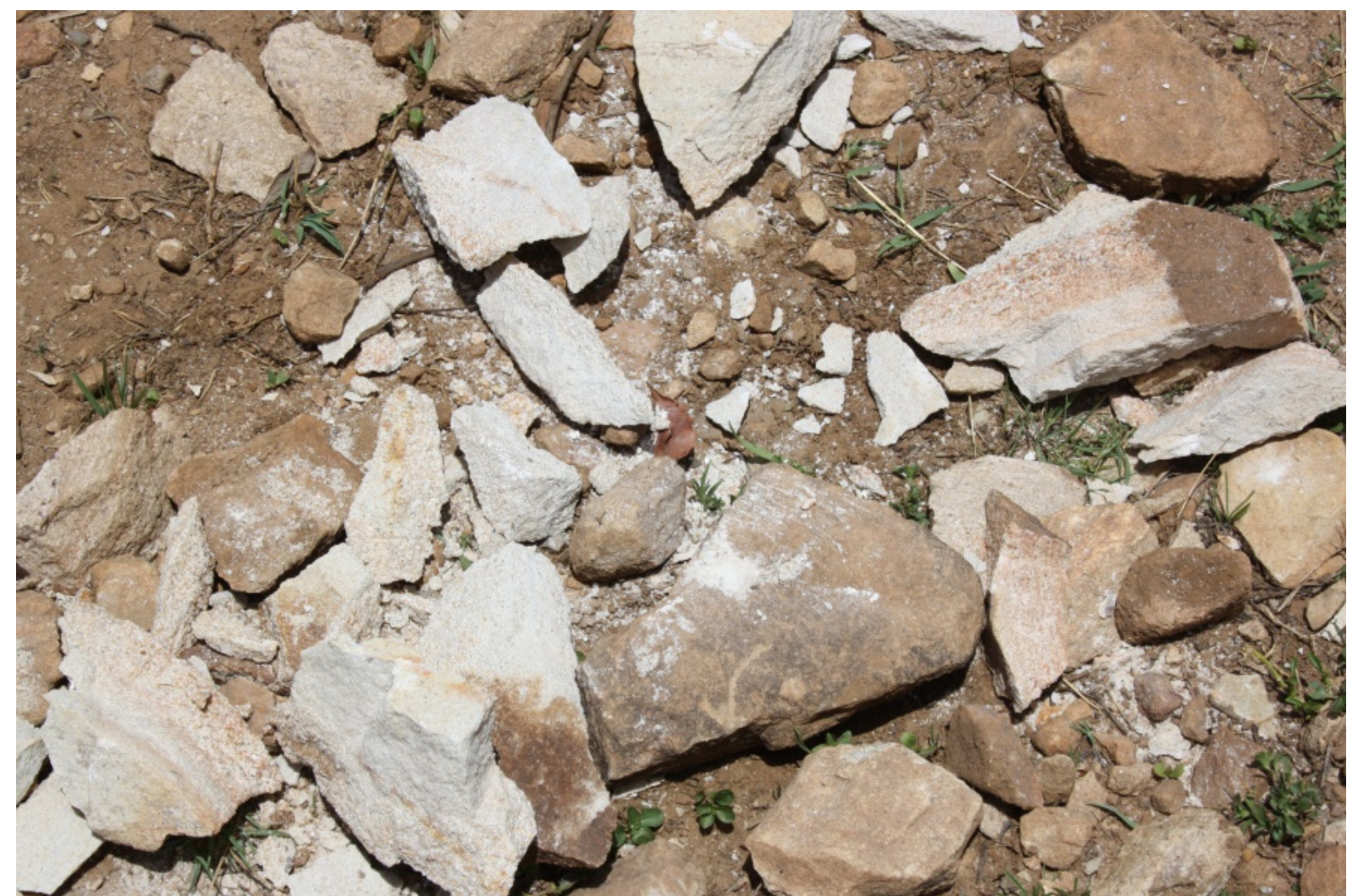

Figure 12. The debitage scattered at manufacturing site.

The finished mathan was plano-convex in shape with only a slightly convex bottom and measured $74 \mathrm{~cm} \mathrm{~L} \mathrm{X} 37 \mathrm{~cm} \mathrm{~W} \mathrm{X} 27 \mathrm{~cm} \mathrm{D}$. We were told by women from the village that this was an excellent mațhan when they saw it, because it was a good size to be effective for grinding, it was of good raw material that would not shed sand when grinding, and it was nicely finished. What was being discovered through interviews throughout the villages was that a good mațan could last 50+ years. When we showed our grinding stones to four local women later, they advised us this particular mațhan could last 30 or more years. Women interviewed had also indicated that larger mațhan were better as they could grind more flour, creating efficiency. A madit artefact dating to the archaic period at Mezber has a grinding surface of $286 \mathrm{~cm}^{2}$ where the newly manufactured madit by the experts had a surface measuring $700 \mathrm{~cm}^{2}$.

These are large grinding stones, with handstones large enough to require two hands for manoeuvring when grinding. Understanding the heavy reliance on grains as a major food in this culture, the larger grinding surfaces supports the findings by Adams (1993), that with the increase in intensity of grinding to increase production due to an increased demand, a larger grinding surface promotes grinding efficiency.

\subsection{Manufacturing the Madit handstone}

A similar process took place to manufacture the madit, though excavation was not required as a smaller loose stone was selected. During the selection of a rock to produce a madit we witnessed various rocks being tapped with a small hammer to produce sounds discernible to the expert. During this selection process rocks were also held and turned in their hands as they sought the right shape and size. These selection decisions were again being used to determine the best available raw materials for the intended end use.

The length of the madit needs to equal the width of the mațhan, and that was the criteria for choosing a suitable size stone. The men also said that they took into consideration how 
much trimming would be required to achieve the desired size and shape, so the closer in shape and size the stone was to the desired finished madit, the less labour it would take to complete, reflecting design decisions that would optimize time and energy. They also considered the end user and how large a madit that person might be able to handle.

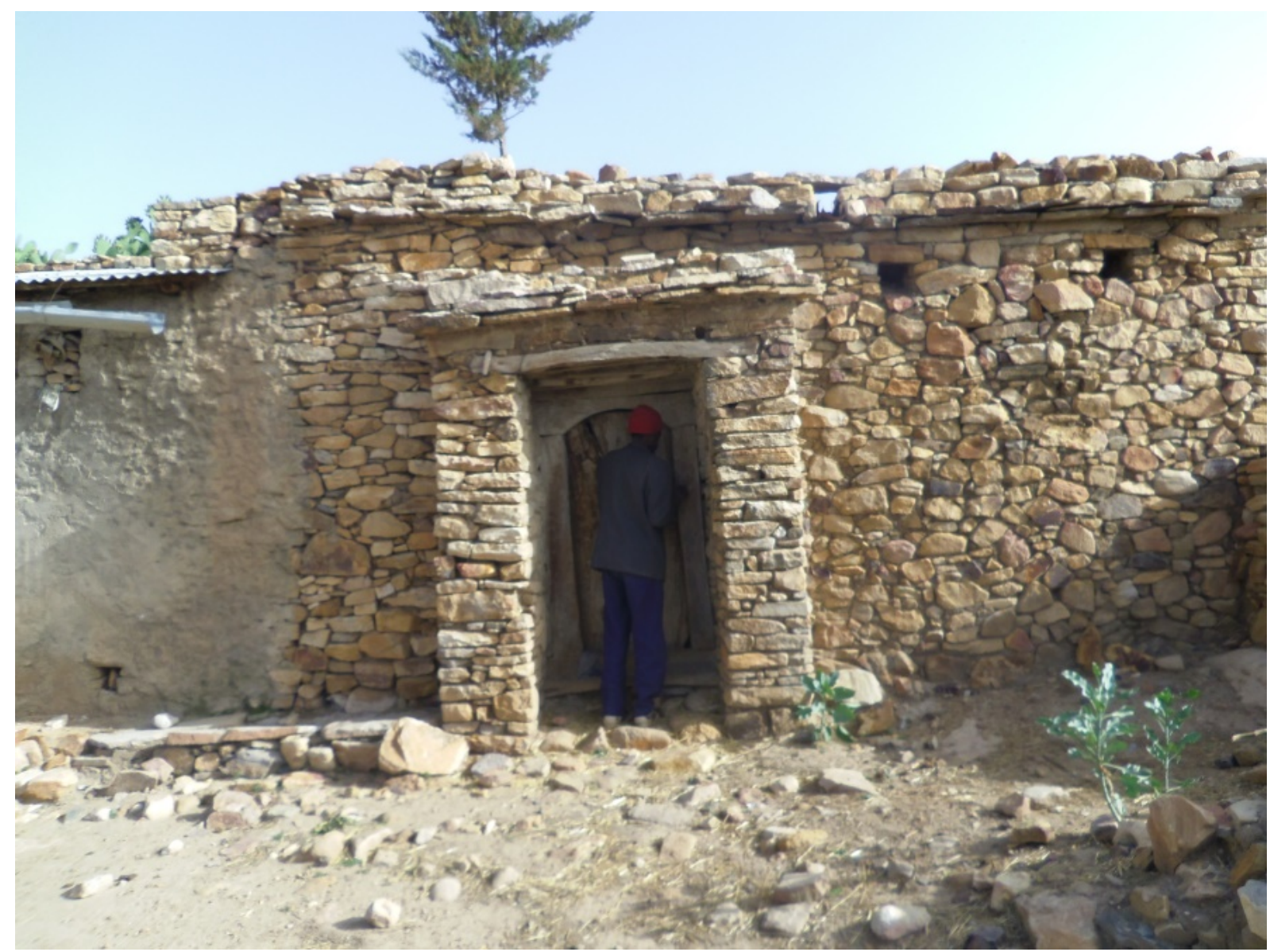

Figure 13. An example of a northern Ethiopian house constructed from stone.

One difference in the manufacturing of the madit was that the initial stone selected suddenly cracked in half during the trimming process. Although the broken halves were examined to see if one could still be used for the madit, it was determined that they were too small and now inappropriate for grinding stones, but we were advised that these halves would be used to build a house.

When the shape and size was roughly what was needed for the madit, it was matched to the maţhan to determine fit. Comments were made to us that the fitting of the madit to maţan was very important. If they did not fit well, grinding surface to grinding surface coming into contact, the grinding effort would be difficult or would be ineffective in producing finely ground flour because the surfaces must come into contact to grind the grains. Without contact the grains would roll around in the gaps and not get ground.

Fine finishing work on the madit entailed further shaping and smoothing through hammering, or chipping of smaller and smaller flakes. The efforts in this phase were detailed and meticulous. The technique witnessed was to land many small, light hammer blows, creating the rounded oval ('loaf') shape needed for the madit. This precise work was less strenuous, but appeared very intense. Several times over the course of the final finishing, the madit was slid over the grinding surface of the mațan to compare fit. Using a typical reciprocal grinding motion for the test the experts checked to determine if the surfaces were 
coming into contact without unwanted resistance between the surfaces. If contact was not being made, or resistance was present, more adjustments were made by continued hammering. The debris removed during this process was small flakes and dust like particles.

The production was complete. For details of transportation (Figure 14) and post manufacturing resharpening see Nixon-Darcus (2014: 101, 102-104).

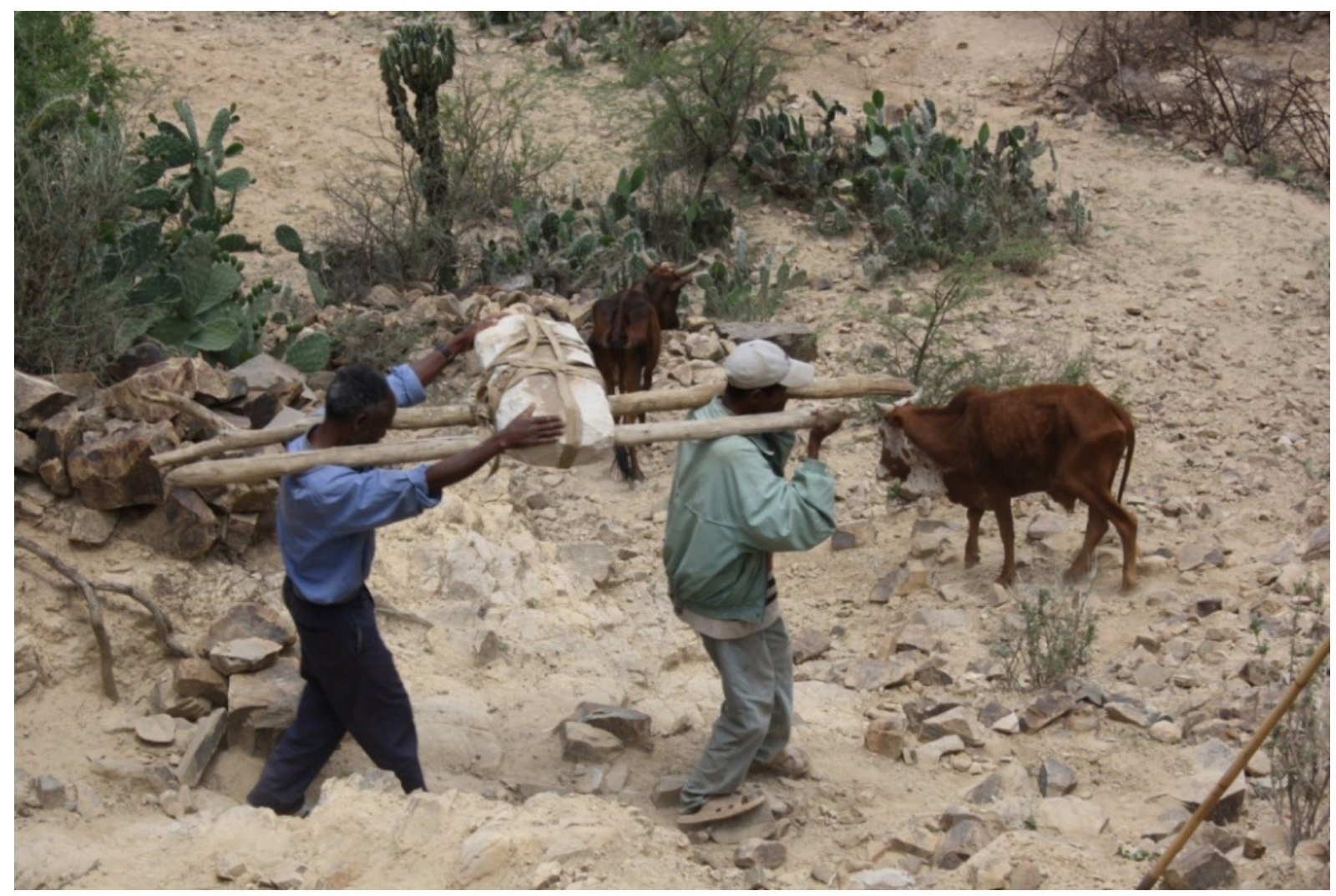

Figure 14. Men transporting the mațhan (quern) using a melde.

\subsection{The non-experts}

In another area of Gulo Makeda we asked who could make a pair of grinding stones. Because mechanical mills had been available to these villages for almost ten years, the need for grinding stone production had diminished. There were no living experts left, however three men advised that they knew how to make grinding stones and offered to make a pair.

The day started with the men seeking the right boulder by knocking off pieces to inspect the interior composition of the stones. However even after checking the composition they broke several boulders in the initial stages of shaping the quern in a way that made it unusable so then had to search for another boulder to begin again. Five different boulders were broken before they were successful in finding one that could be hammered into shape without large sections of the boulder breaking off.

It was noted that at times the men struggled with the tools, breaking the tools and having to stop to fix them. These men used sledge hammers for most of the shaping, rather than using some finer tools as was witnessed of the experts' process. This resulted in less finely finished grinding stones with rough edges and surfaces and irregular overall shapes.

The key differences between experts and non-experts are further discussed under Section 4. 


\section{Interpretations of the data}

\subsection{Design decisions, expert knowledge and status}

In the ethnoarchaeological data analysis the difference between expert made and nonexpert made grinding stones was clear in their design decisions, knowledge about raw materials, their understanding of how the stone reacts to tools used to break-shape-trim and finish the grinding stones, the finer finishing work of the experts and the attention to user needs. The experts would tap the boulder to determine the quality of the stone, where the nonexperts broke several boulders before they found one that would be suitable. The experts showed better knowledge of how the stone would react to force shearing off chunks and flakes efficiently and effectively. This was not as obvious with the non-experts, as they needed to correct areas that did not trim properly. The experts produced a finely finished and symmetrical pair of grinding stones, whereas the non-experts presented a rough finish and not as symmetrical. It was apparent the experts have the user in mind when making design decisions because the grinding stones they made for me were manageable for my body size and strength and the finely finished ends and edges were comfortable in my hands. The madit made by the non-experts was too heavy for me to lift or manipulate and was very rough on the skin of my hands. Most males who had manufactured mentioned that they consult with their wives prior to making the grinding stones but it was only the experts who mentioned they consider the size of the person who will be using the tools when determining the size to manufacture. David (1998) also comments on the possibility of user body size influencing the size of grinding hollows in west Africa. For other cross-cultural comparisons on different aspects of manufacturing see Nixon-Darcus (2014).

In eastern Tigrai much of men's time is spent on farming and grinding stones would be produced as needed. Considering how long a mațan can last (50 plus years as suggested by consultants), and if the population was rural as is suspected at the archaeological site of Mezber, the local need in the past would have been occasional, reflecting the need for only part time specialists. Despite being a part time career, it is clear that the manufacturing of grinding stones in northern Ethiopia by men is a complex process that requires design decisions, skills and knowledge, and social interaction that builds interpersonal relationships. In addition, the individuals who are or were experts in the field of manufacturing grinding stones are afforded a special respect, the creators of technology "necessary for life" in a culture so dependent on flours for sustenance. This special respect afforded grinding stone makers is important because in other parts of Ethiopia as well as cross-culturally, craft specialists are often marginalized, of a lower status or class (Arthur 2014; Cook 1982: 129, 131, 175). "Craft specialist" is a term often used by archaeologists, however as Costin (1991; 2007) points out, specialization takes many forms. The grinding stone makers near Mezber would fall under her definition of a part-time independent specialist who produces for the general market as demand requires (Costin 1991; 2007).

The master craftsmen of grinding stone manufacturing near Mezber are highly respected for their knowledge and skills. Searcy (2011) refers to long apprenticeships for the Maya matateros (grinding stone manufacturing experts). The experts I interviewed who learned from their fathers beginning in their early teens said that they could learn the basics after a few experiences, but that it would take a long time to master the craft. For the Gamo of southern Ethiopia mastering the craft takes 15 years (Arthur 2014). The added skills and knowledge acquired through long apprenticeships became apparent when observing the expert and non-expert manufacturing sessions. 


\subsection{Social relations and values}

Using the chaîne opératoire approach the steps of manufacturing were broken down. Each step was observed to understand the specific steps in the process and to record each step, and also to observe the interrelationships between the technology under construction and the wider cultural milieu. Social relations and values were expressed in several ways.

The social framework embedded in the manufacturing process was manifested in the hierarchy of status of the men based on their expertise and knowledge, and the respect that they garnered from others in the group, as discussed above. However, it was not all work, no play, on the day of manufacturing. We noted that the men took time to eat, drink, talk, laugh, sing, and have general discussions including updates on community issues. We heard from many of the male informants during our ethnoarchaeological interviews that singing, laughing, discussions and drinking sua (a local beer) were key components of the socialization that happens when a group of men get together to manufacture grinding stones. This solely male based activity provided a time for building, or perhaps maintaining, social relationships. With fewer and fewer grinding stones being manufactured this particular opportunity for male interaction and socialization was disappearing, and through the interviews we learned that some men were going to miss these opportunities for interaction, though they commented that they would not miss the hard work.

The value of "cooperation" in the community was also suffering. Haleka Tehwoeldebrahn told us that in the past, if they started to hammer a stone the sound would carry through the valley and as men heard the hammer sounds, they would make their way to help with the manufacturing of the maţhan, but this was no longer the case. No one came to help, but rather he had had to arrange for extra help in advance. Values are changing as the people of this valley come to rely more and more on the cash economy and the men are too busy earning to help.

Religious values manifested during the manufacturing process through behaviors displayed. The repeated chant "Help me Hail Mary" reflected a belief in supernatural aid that could be requested by human believers in need of assistance. In addition, we had been informed that the men could not do heavy work on 'holy days', revealing the adherence to religious traditions.

\section{Conclusions}

Although there are problems associated with applying ethnographic data directly to explain archaeological discoveries because of the temporal differences, through analogy we can build interpretations and understandings of the past. According to David and Kramer (2001: 2), ethnoarchaeology can provide the researcher a privileged position in relation to interpreting the material culture and the associated human behaviors relating to it, particularly where the ethnography is with likely decedents of those who created the archaeological record. In the archeological record of northern Ethiopia, grinding stones are being recovered from the pre-Aksumite period (1600 BCE - 1 BCE, CE), and are very similar morphologically to the grinding stones in the houses around the archaeological sites of Mezber and Ona Adi today.

In an effort to better understand the grinding stone artifacts being excavated, research has been conducted on the grinding stones of today, including the witnessing of the production process by both experts and non-experts which revealed the complexity of manufacturing and the special knowledge held by the experts. It is fortunate that we have had the opportunity to witness and document manufacturing processes that have likely existed for thousands of years in northern Ethiopia, first with stone tools and more recently during the lifetime of current expert manufacturers those skills were applied using metal tools. The men involved in the 
manufacturing learned the skills and acquired the knowledge from their fathers, who learned from their fathers, who also learned from their fathers, far back into the generations.

Through ethnoarchaeology it became clear that the manufacturing of grinding stones in northeastern Tigrai is a complex process that requires design decisions, skills, knowledge, and social interaction that builds interpersonal relationships. Using a design theory perspective it was learned that manufacturers were faced with constraints and choices such as: 1) raw material - it took additional work to excavate a stone with the right qualities, where the men could have picked a loose boulder from the surface, the constraint was the need to perform extra work to get the better raw material; 2) tools available - in the past constraints were related to stone tools only being available, now the tools are metal but there is still no access to power tools that could make the job easier; 3) desired use life - thicker grinding stones for longer use life were the goal but they were heavier to carry back presenting a constraint and a choice; 4) user needs and preferences - women could refuse grinding stones that did not meet their expectations creating the need for manufacturers to make design decisions to meet individual needs reflected when the experts took into account my small physical size and ability producing an appropriate size handstone for me to work with that was easier to use. The non-experts made a handstone far too heavy for me to move effectively; and 5) performance expectations, in particular the requirement for grinding stones that do not release sand while grinding, and this relates back to the raw material choice.

By arranging two separate manufacturing sessions, one with experts, one with nonexperts, comparisons were made possible that allowed for discovery of technological and social differences between the experts and non-experts. From a technological perspective the experts made superior grinding stones which were nicely finished, made of finer quality materials, and a finished size more suitable for my stature. The social difference is that the experts are afforded a special respect by people in their community because in a culture so dependent on cereal flours for sustenance these men are the creators of the technology "necessary for life" (a quote from my interviews around Mezber). The modern grinding stones are large in size, and large stones grind more flour (Adams 1993; Fratt \& Biancaniello 1993; Hard et al. 1996; Mauldin 1993; Searcy 2011: 59). According to the women I interviewed, these large grinding stones were required for efficient grinding of approximately 22 kilograms of flour every second day, the amount needed to feed their families. The preAksumite Mezber grinding stones are large stones as well and were likely meant to produce similar amounts of flour reflecting a large contribution to the diet of that day. The archaeological grinding stones used to produce flour would have been important to daily life and sustenance and therefore it is probable that the makers of those tools would have been important people in the community. Potentially, the type of respect for modern experts could have existed for the experts of the past as well, since is it is possible that the grinding stone artifacts from Mezber were also "necessary for life".

\section{Acknowledgements}

First, I would like to sincerely thank my supervisor A. Catherine D'Andrea who patiently guided me through this research and provided much support and encouragement. My greatest thanks also go to the residents of Gulo Makeda who welcomed us into their communities and shared their knowledge, expertise, and memories. I would especially like to acknowledge the men who produced our grinding stones, especially Haleka Tehwoelde Brahn Beyene and Haleka Gebreselassie Gebreyesus. I benefited greatly by the participation of our interpreters, Yemane Meresa and Habtamu Mekonnen who deserve special recognition for their contribution to this research. Without their understanding of the language, and customs, I would not have succeeded in obtaining the information needed. Transliterations for many 
Tigrinya terms were provided by Professor Yaqob Beyene, Department of Asia, Africa, and the Mediterranean, University of Naples, and additional Tigrinya terms were translated by Yemane Meresa. Many thanks to the Authority for Research and Conservation of Cultural Heritage (ARCCH), especially Ato Desalgen Daad, as well as the Tigrai Agency for Tourism and Ato Kebede Amare, for support in gaining governmental permissions. My paper was significantly improved by acting on insightful comments and recommendations made by anonymous reviewers. Funding for this research included the Social Sciences and Humanities Research Council of Canada (SSHRC) through a Joseph Armand Bombardier CGS Master's Scholarship, Standard Research Grant No. 410-2011-1646. Support from Simon Fraser University includes the Provost Prize of Distinction, Graduate Fellowships and Graduate International Research Travel Award.

\section{References}

Abadi-Reiss, Y., \& Rosen, S.A. 2008, A Chip Off the Old Millstone: Grinding Stone Production and Distribution in the Early Bronze Age of the Negev. In: New Approaches to Old Stones (Rowan, Y.M., \& Ebeling, J.R., Eds.), Equinox Publishing Limited, London: p. 99-115.

Adams, J. L. 1993, Toward Understanding the Technological Development of Manos and Metates. Kiva 58(3, New Trends in Ground Stone Research: It's Not the Same Old Grind): 331-344. doi:10.1080/00231940.1993.11758213

Adams, J. L. 2014, Ground Stone Analysis: a technological approach. The University of Utah Press, Salt Lake City, 318 p.

D'Andrea, A. C. 2008, T'ef (Eragrostis tef) in Ancient Agricultural Systems of Highland Ethiopia. Economic Botany, 62(4): 547-566. doi:10.1007/s12231-008-9053-4

D'Andrea, A. C., \& Haile, M. 2002, Traditional Emmer Processing in Highland Ethiopia. Journal of Ethnobiology, 22(2): 179-217.

D’Andrea, A. C., Haile, M., Butler, E.A., \& Lyons, D.E. 1997, Ethnoarchaeological Research in the Ethiopian Highlands. Nyame Akuma, 47: 19-26.

D'Andrea, A. C., \& Wadge, P. 2011, T'ef (Eragrostis tef): A Legacy of Pastoralism?. In: Windows on the African Past: Current Approaches to African Archaeobotany. Reports in African Archaeology, Vol. 3 (Fahmy, A.G., Kahlheber, S., \& D’Andrea, A. C., Eds.), Africa Magna Verlag, Frankfurt: p. 547-566.

Arthur, J. W. 2014, Culinary Crafts and Foods in Southwestern Ethiopia: An Ethnoarchaeological Study of Gamo Groundstones and Pottery. African Archaeological Review, 31(2): 131-168. doi:10.1007/s10437-014-9148-5

Binford, L. R., (Ed.), 1977, For Theory Building in Archaeology. Academic Press, New York, $419 \mathrm{p}$.

Clarkson, C., Jacobs, Z., Marwick, B., Fullagar, R., Wallis, L., Smith, M., Roberts, R.G., Hayes, E., Lowe, K., Carah, X., Florin, S.A., McNeil, J., Cox, D., Arnold, L.J., Hua, Q., Huntley, J., Brand, H.E.A., Manne, T., Fairbairn, A., Shulmeister, J., Lyle, L., Salinas, M., Page, M., Connell, K., Park, G., Norman, K., Murphy, T., \& and Pardoe, C. 2017, Human occupation of northern Australia by 65,000 years ago. Nature, 547: 306-310. doi:10.1038/nature22968 
Conlee, C. A. 2000, Intensified Middle Period Ground Stone Production on San Miguel Island. Journal of California and Great Basin Anthropology, 22(2): 374-391.

Cook, S. 1982, Zapotec Stoneworkers: the dynamics of rural simple commodity production in modern Mexican capitalism. University Press of America, Maryland, 432 p.

Costin, C. L. 1991, Craft Specialization: Issues in Defining, Documenting, and Explaining the Organization of Production. Archaeological Method and Theory, 3: 1-56. doi:10.2307/20170212

Costin, C. L. 2007, Thinking about Production: Phenomenological Classification and Lexical Semantics. Archeological Papers of the American Anthropological Association, January 2007, Vol.17(1): 143-162. doi:10.1525/ap3a.2007.17.1.143

David, N. 1998, The Ethnoarchaeology and Field Archaeology of Grinding at Sukur, Adamawa State, Nigeria. The African Archaeological Review, 15(1): 13-63. doi:10.1023/A:1022270208256

David, N., \& Kramer, C. 2001, Ethnoarchaeology in Action. Cambridge University Press, Cambridge, 476 p. doi:10.1017/CBO9781316036488

Field, J. H., Fullagar, R., Dortch, J., Dutkiewicz, A., \& Gordon, P. 2003, Sandstone Quarries and Grinding Stone Manufacture: Survey and Excavation at Yambacoona Hill in SouthEastern Australia. Australian Archaeology, 56: 46-47. doi:10.1080/03122417.2003.11681750

Fratt, L., \& Biancaniello, M. 1993, Homol'ovi III Ground Stone in the Raw: A Study of the Local Sandstone Used to Make Ground Stone Artifacts. Kiva, 58(3, New Trends in Ground Stone Research: It's Not the Same Old Grind): 373-391. doi:10.1080/00231940.1993.11758216

Hard, R. J., Mauldin, R.P., \& Raymond, G.R. 1996, Mano Size, Stable Carbon Isotope Ratios, and Macrobotanical Remains as Multiple Lines of Evidence of Maize Dependence in the American Southwest. Journal of Archaeological Method and Theory, 3(3): 253-318. doi:10.1007/BF02229401

Horsfall, G. A. 1979, A Design Theory Perspective on Variability in Grinding Stones. Master of Arts Thesis at the Department of Archaeology, Simon Fraser University, Burnaby, $133 \mathrm{p}$.

Horsfall, G. A. 1987, Design Theory and Grinding Stones. In: Lithic Studies Among the Contemporary Highland Maya (Hayden B., Ed.), University of Arizona Press, Tucson: p. 332-377.

Jones, J. C. 1970, Design Methods: seeds of human future. Wiley-Interscience, London, 407 p.

Leroi-Gourhan, A. 1993, Gesture and Speech. (Translated by Bostock Berger, A.). MIT Press, Massachusetts, $431 \mathrm{p}$.

Margolin, V. 1989, Design Discourse: history, theory, criticism. University of Chicago Press, Chicago, $291 \mathrm{p}$.

Mauldin, R. 1993, The Relationship between Ground Stone and Agricultural Intensification in Western New Mexico. Kiva, 58(3, New Trends in Ground Stone Research: It's not the Same Old Grind): 317-330. doi:10.1080/00231940.1993.11758212 
McBrearty, S., \& Brooks A.S. 2000, The revolution that wasn't: a new interpretation of the origin of modern human behavior. Journal of Human Evolution, 39(5): 453-563. doi:10.1006/jhev.2000.0435

Nixon-Darcus, L.A. 2014, The Cultural Context of Grinding Equipment in Northern Ethiopia: An Ethnoarchaeological Approach. Master of Arts Thesis at the Archaeology Department, Simon Fraser University, Burnaby, 343 p.

Pye, D. 1978, The Nature and Aesthetics of Design. Van Nostrand Reinhold, New York, 159 p.

Sandgathe, Dennis, personal communication at Simon Fraser University, June 2013.

Schneider, J.S., \& Altschul, J.A. 2000, Of Stones and Spirits: Pursuing the Past of Antelope Hill. Technical Series 76. Statistical Research Inc., Tucson, 215 p.

Schneider, J. S. 1996, Quarrying and Production of Milling Implements at Antelope Hill, Arizona. Journal of Field Archaeology, 23(3): 299-311. doi:10.2307/530484

Searcy, M. T. 2011, The Life-Giving Stone: ethnoarchaeology of Maya metates. University of Arizona Press, Tucson, 168 p.

Smith, M., McBryde, I., \& Ross, J. 2010, The economics of grindstone production at Narcoonowie quarry, Strzelecki Desert. Australian Aboriginal Studies, 2010(1): 92-99.

Teklu, G. 2012, Ethnoarchaeological Study of Grind Stones at Lakia'a in Adwa, Tigray Regional State, Ethiopia. Master of Arts Thesis at the Department of Archaeology and Heritage Management, Addis Ababa University, Addis Ababa, 103 p. 